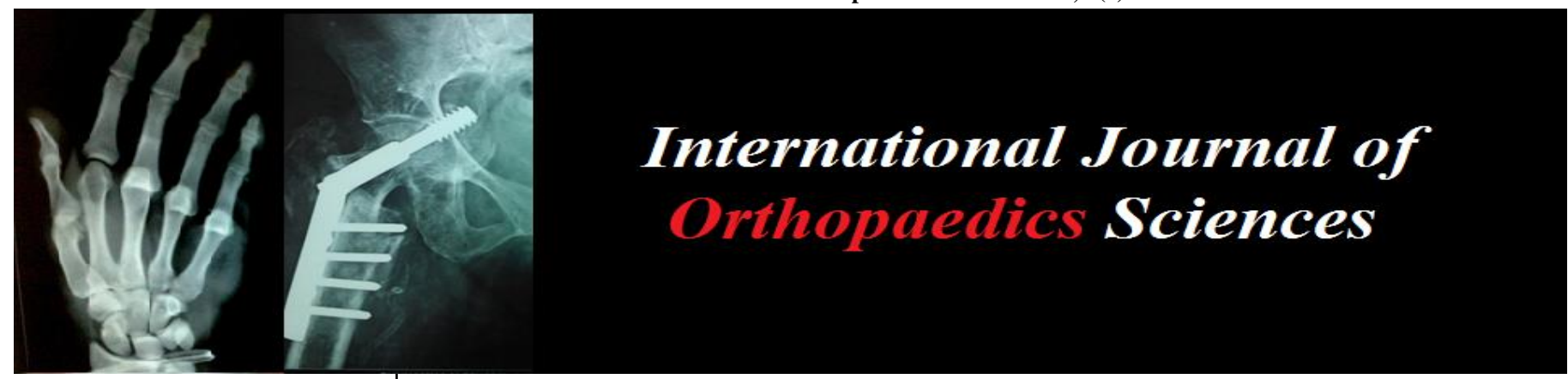

E-ISSN: 2395-1958

P-ISSN: 2706-6630

IJOS 2020; 6(3): 60-63

(C) $2020 \mathrm{IJOS}$

www.orthopaper.com

Received: 07-05-2020

Accepted: 09-06-2020

T Suresh Kumar Gupta

Assistant Professor, S.C.B.

Medical College and Hospital,

Cuttack, Odisha, India

Tapasa Kumar Panigrahi

Assistant Professor, S.C.B.

Medical College and Hospital,

Cuttack, Odisha, India

Dillip Kumar Chand

Senior Resident, S.C.B. Medical

College and Hospital, Cuttack,

Odisha, India
Corresponding Author:

Tapasa Kumar Panigrahi

Assistant Professor, S.C.B.

Medical College and Hospital,

Cuttack, Odisha, India

\section{Anatomical \& functional outcome of colles' fracture in geriatric population: A prospective study}

\author{
T Suresh Kumar Gupta, Tapasa Kumar Panigrahi and Dillip Kumar \\ Chand
}

DOI: $\underline{\text { https://doi.org/10.22271/ortho.2020.v6.i3b.2178 }}$

\section{Abstract}

Introduction: Perkins warranted that Colles' fracture however skill fully treated may leave behind a deformed wrist ${ }^{[1]}$. As the disability has been attributed to the deformity, therefore obtaining the anatomical reduction has been emphasised. Aim of the study was to evaluate the results of conservative treatments of Colles' fracture, in terms of radiological and functional outcome, their relationship with each other, and to found out the acceptable measurements of radiological parameters for better functional results.

Material \& Methods: This prospective study included 50 patients of extra articular Colles' fracture, was carried out in the Department of Orthopaedic from May 2017 to May 2019. All patients were immbolized with a below elbow cast for 4 weeks and followed up at 3 months and 6 months. Radiological assessment was done by measuring dorsal angulation, loss of radial inclination and loss of radial height as per Stewart et al. and functional assessment was done by criteria by Mayo wrist scores.

Results: Excellent and good results was obtained in $72.5 \%$ anatomically and $82.5 \%$ functionally at 6 months, with a statistically significant association between them. Out of the three anatomical parameter as criteria led by Stewart et al. dorsal angulation $<10$ degrees and loss of radial inclination $<9$ degrees showed statistically significant association with functional results. But loss radial height $<6 \mathrm{~mm}$ did not show statistically significant association.

Conclusion: As there was a statistically significant association between the radiological and functional results, therefore obtaining a acceptable anatomical reduction of the fracture is emphasised, and acceptable radiological parameters were, dorsal angulation was $<10$ degrees, loss of radial inclination $<$ 9 degrees and loss of radial height was $<4 \mathrm{~mm}$ for obtaining excellent or good functional results.

Keywords: Colles' fracture, conservative, anatomical parameter, mayo wrist score

\section{Introduction}

Colles' fracture is a very common fracture about (10-17\%) seen in geriatric age group between 60-70 years especially in female ${ }^{[2-4]}$. And most of the time it is treated in OPD basis with below elbow cast with wrist in neutral to slight palmar flexion and ulnar deviation. But most of the time, it unites with a typical deformity of radial deviation and dorsal translation i.e. Dinner fork deformity ${ }^{[3]}$ As most of the orthopaedicians think that Colles' fracture does not need special attention as the resulting deformity rarely damage wrist function, but there exist a second thought that Colles' fracture can lead to poor functional outcome, especially in older age group and some author have noted above $17 \%$ had poor function one year after injury [5] Some have noted good functional result in spite of deformed wrist at six month after fracture. The disability after Colles' fracture has been attributed to the deformity and therefore obtaining the anatomical reduction has been emphasised.

Hence we performed a prospective study to assess the anatomical/radiological and functional results of the conservative treatment of the Colles' fracture at long term and we analyse the correlation between the individual parameter of anatomical/radiological results(dorsal angulations, loss of radial inclination, loss of radial length) with functional result to know which radiological parameter actually affects the functional outcome and to determine the borderline value of the radiological parameter. 


\section{Material \& Methods}

In a 2-year period between May 2017 and May 2019, Data were prospectively collected \& analysed for 50 patients with distal radius fracture (AO/OTA-2R3A2.2), who attended the outdoor and emergency care unit at Department of Orthopaedic. The patients were treated by below elbow cast immobilisation for 4 weeks and evaluated in terms of anatomical result and functional out come.

\section{Inclusion criteria}

- Age- 60-80 years

- Unilateraldistalradiusfracture

- Extra-articular fracture

- Closed fracture

\section{Exclusion Criteria}

- Age $<60$ yr \& $>80$ yrs

- Bilateral distal radius fracture

- Intra articular fracture

- Open fracture

The patients are classified according to AO/OTA classification. Standard series of PA (Postero anterior) \& lateral of both wrist (injured \& Healthy side) are taken to visualise the suspected fracture. After giving a hematoma block (with $1 \mathrm{ml}$ of $2 \%$ lignocaine) followed by closed manipulation under the image intensifier guidance. After achieving the acceptable anatomical reduction of the fracture, the forearm was immobilized by below elbow plaster cast for 4 weeks. After cast removed patient underwent supervised hand, wrist, elbow, shoulder physiotherapy to prevent stiffness and then followed up at 3 month and 6 month interval for anatomical \& functional evaluation.

The functional outcome was measured by Mayo wrist score at 6 month after fracture healing. A Goniometer was used for the measurement of the flexibility of wrist joint of the healthy and injured hand. Dynamometer was used to measure the grip strength.

The anatomical or radiological outcome was assessed by taking $\mathrm{X}$ ray of both wrist and compared with each other according to criteria established by Bilic et al. ${ }^{[14]}$ by determining radial inclination, dorsal angulation, and loss of the radial bone length. Anatomical results (Table 1) were assessed on the basis of criteria established by Stewart $e t$ al. ${ }^{[6]}$ and the overall anatomical parameter was compared with functional outcome at minimum 6 month of fracture healing along with individual parameter too.

According to Stewart et al., acceptable dorsal angulation was 10 degrees, acceptable loss of radial inclination was 9 degrees, and acceptable loss of radial bone length was $6 \mathrm{~mm}$ ${ }^{[6]}$ (Table 1).

Table 1: Anatomical assessment of treatment results of radial bone fracture in a typical zone:

\begin{tabular}{|c|c|c|c|}
\hline $\begin{array}{c}\text { Dorsal angle } \\
\text { (Dgrees) }\end{array}$ & $\begin{array}{c}\text { Loss of radial } \\
\text { Length (mm) }\end{array}$ & $\begin{array}{c}\text { Loss of Radial } \\
\text { Angle (dgrees) }\end{array}$ & Score \\
\hline Neutral & $0-3$ & $0-4$ & 0 \\
\hline $1-10$ & $4-6$ & $5-9$ & 1 \\
\hline $11-14$ & $7-11$ & $10-14$ & 2 \\
\hline$>15$ & $>12$ & $>15$ & 4 \\
\hline
\end{tabular}

[Rating: combined score dorsal angle, radial length, and radial angle; Excellent=0; Good=1-3; Fair=4-6; Poor $=7-12$ )

\section{Statistical Analysis}

We analyzed functional result of two groups using chi-square test of association. P-value $<0.001$ was considered statistically significant. To examine strengths of associations, we computed odds ratios (OR) with $95 \%$ confidence intervals (CI) for the functional result in relation to the anatomic result

\section{Results}

Of the 50 patients included, 27 were female and 23 were male. The mean age of $69.3 \pm 3$.6years (range, $60-80$ years). In 45 patients the right hand was dominant, whereas in 5 patients left hand was dominant. In 32 patients, the fracture occurred in the dominant and in 18 patients in the non-dominant hand. The incidence of fracture was highest in patients aged 60-69 years. In this age group, the incidence of fractures was higher in women than in men (there were 20 men and 24 women in age group 60-70 years), which corresponds with data reported in literature ${ }^{[3,5]}$.

Table 2: The demographics and clinical charactaristic of patients

\begin{tabular}{|l|l|}
\hline Patients(N) & 50 \\
\hline Mean Age(years) & $69.3 \pm 3.6(60-80 \mathrm{yrs})$ \\
\hline Female patients & $27(54 \%)$ \\
\hline Male patients & $23(46 \%)$ \\
\hline Affected side: & 32 \\
- Unilateral, dominant hand & 18 \\
- Unilateral, non dominant hand & \\
\hline Radiological parameter of Control Hand: & $20-30^{0}(25.6 \pm 2.8$ degree $)$ \\
- Radial inclination & $0-15^{\circ}(7.9 \pm 4.2$ degree $)$ \\
- Palmar Agulation & $8-18 \mathrm{~mm}(13.4 \pm 1.7 \mathrm{~mm})$ \\
\hline
\end{tabular}

Table 2: The demographics and clinical charactaristic of patients

The functional result was excellent in 34 patients, good in 07 patients, fair in 5 \&poor in 4 patients. The anatomical result was excellent in 26 patients, good in 10, fair in 08, and poor in 06 patients minimum at 6 months. Hence anatomically excellent or good results achieved in 36, fair or poor in 14 and functionally excellent or good results seen in 41 and fair or poor in 9 patients. [Chi-square $=9.899$, d.f. $=1$. 


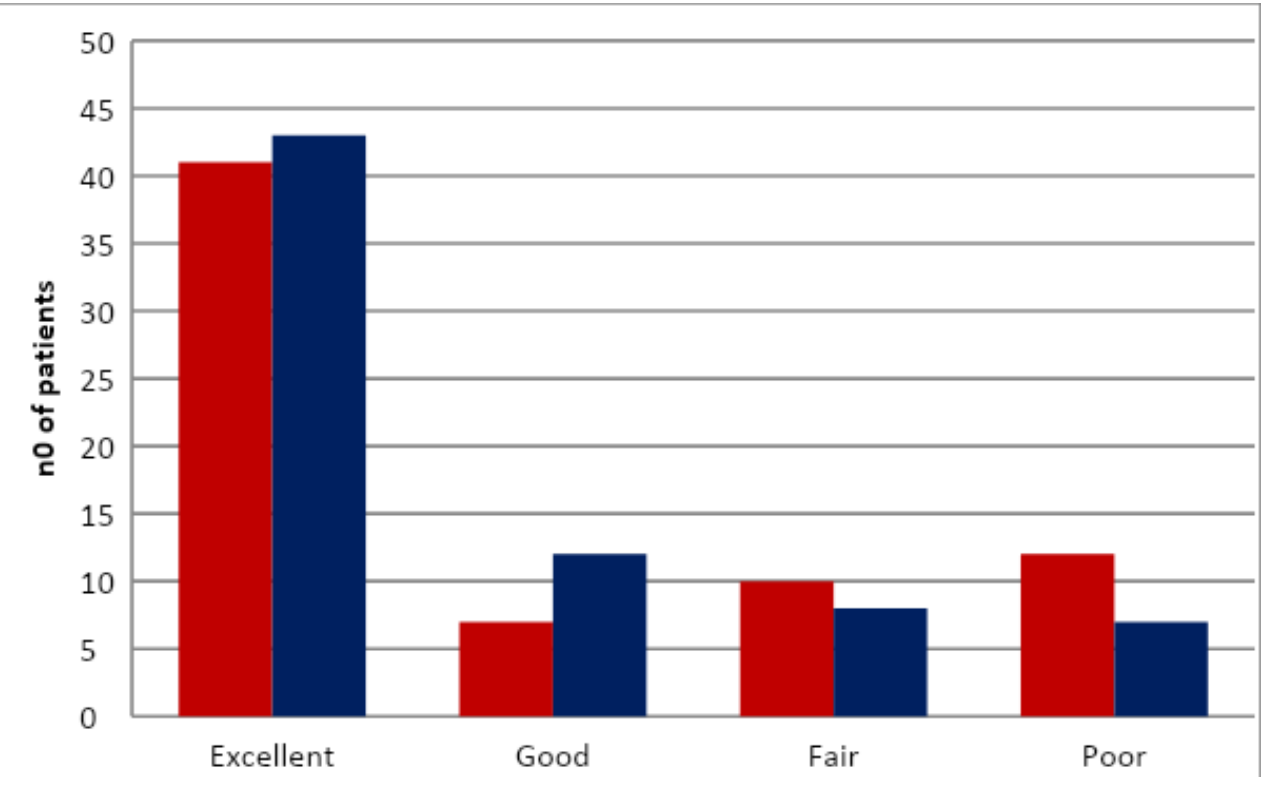

Graph 1: (Bar diagram showing the anatomical and functional outcome of Colles' fracture at 6 month)

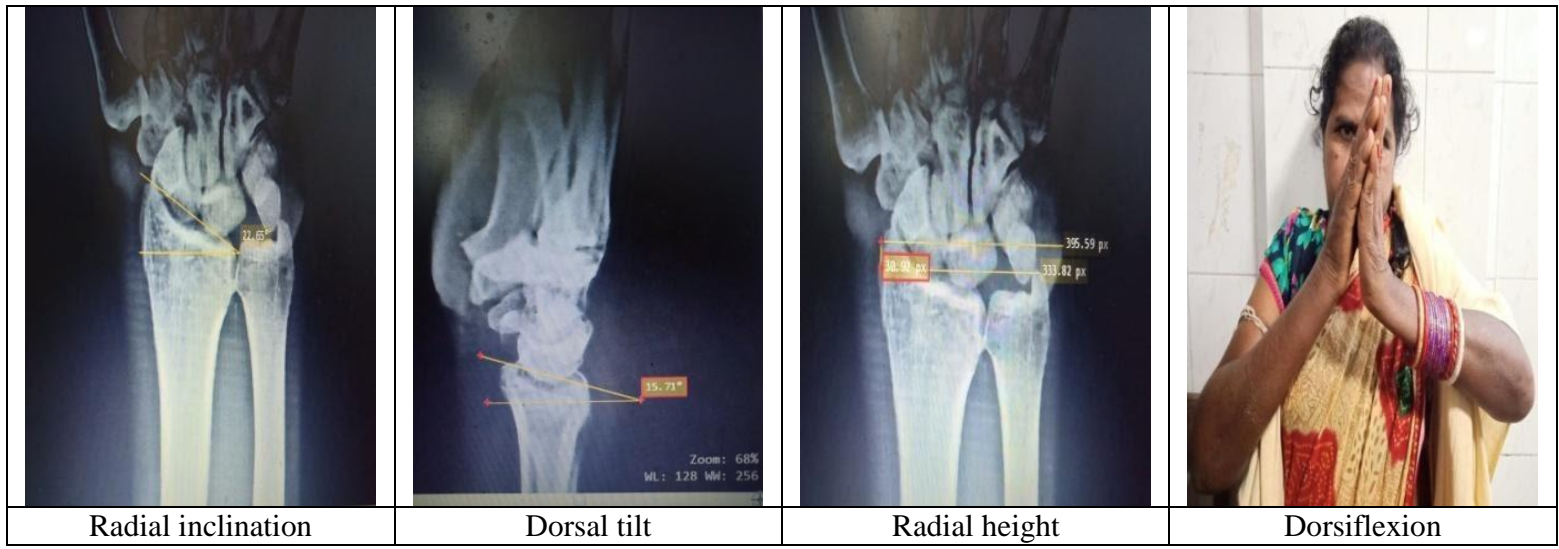

Fig 1: (FollowupofaColles'fractureat6month.)

Out of 50 patients dorsal angulation was $<10$ degree in 42 patients, $>10$ degree in 08 patients at 6 months. There was a statistically significant association was found between the dorsal angulation and functional results at 6 months. [Chisquare $=11.57$, d.f. $=1, p<0.001$. Odds ratio $=6.76$.

Out of 50 patients loss of radial angulation was $<9$ degree in 35 patients, $>9$ degree in 15 patients) at 6 months. There was a statistically significant association was found between the loss of radial angulation and functional results at 6 months. [Chi-square $=11.77$, d.f. $=1, \quad p<0.001(0.0006)$. Odds ratio $=7.67$.

Out of 50 patients loss of radial height was $<6 \mathrm{~mm}$ in 41patients,> $6 \mathrm{~mm}$ in 9 patients at 6 months. There was no statistically significant association was found between the loss of radial height and functional results at 6 months. [Chisquare $=6.62$, d.f. $=1, \mathrm{p}>0.001(0.01)$. Odds ratio $=4.57$.

But when loss of radial height is kept to less than $4 \mathrm{~mm}$,out of 50patients $<4 \mathrm{~mm}$ loss in radial height is noted in 31 patients. $>4 \mathrm{~mm}$ loss of radial height noted in 19 patients. There was statistically significant association was noted between loss of radial height and functional result at 6 month. When loss of radial height is less than $4 \mathrm{~mm}$. (Chi-square=10.07,d.f. $=1$, $p<0.001$.odds ratio $=9.48,(95 \% \mathrm{CI})$

\section{Discussion}

Due to a wide range of measured parameters in healthy hands, it is necessary to make a comparative X-ray of both wrists, because measured parameters in healthy hand can be used as control criteria for the assessment of treatment results. In our study, the radial inclination in healthy hands ranged from 2030 degrees, which is in accordance with literature data ${ }^{[9,10]}$. However, the mean value of radial inclination is $25.6 \pm 2.8$ degrees, which is higher than the 20 degree average described by Metz et al, $22^{0}$ described by Taleisnik et al or $23^{0}$ reported by Seck ${ }^{[9,11,12]}$. It is close to average radial inclination value of $25.4^{0}$ as reported by Friberg and Lundstrom ${ }^{[13]}$. The palmar tilt in our study ranged from $0-15$ degree, which is in accordance with other relevant studies reporting the range of values from $0-22$ degrees ${ }^{[8,10,13]}$ The mean value of palmar tilt is $7.9 \pm 4.2$ degree, which is lower than most commonly reported average value of 14.5 degrees $[9,10]$. The length of radial bone measured by us was ranged from 8 to $18 \mathrm{~mm}$ (mean value of $13.4 \pm 1.7 \mathrm{~mm}$ ) which is similar to result obtained by Biliac et al. ${ }^{[14]}$

Excellent or good anatomical and functional results were obtained in 35 out of 50 patients, whereas in 15 patients both cast group outcomes were assessed as satisfactory or poor. Our results are close to other studies that found closed reduction and solid cast immobilization acceptable methods of the treatment in $75-80 \%$ of fractures of distal radial bone [7]. We got $75.8 \%$ excellent or good functional result. Cassebaum reported obtaining $94.1 \%$ excellent or good functional results in 135 patients with radial bone fracture ${ }^{[4]}$. Altissimi et al obtained $87 \%$ excellent or good anatomical 
results in 297 patients treated for radial bone fracture by closed reduction ${ }^{[8]}$.

There is significant correlation between anatomical and functional out come at 6 months. We obtained significant correlation between anatomical and functional results, which differs from the results obtained by Gartland and Werley who obtained surprisingly good functional results despite poor repositioning and inadequate immobilization ${ }^{[15]}$. Our results also differ from those reported by Cassebaum, Pool and Young and Rayan who obtained good function in cases where anatomical results were poor ${ }^{[4,16,17]}$. However, the majority of authors report about significant correlation between anatomical and functional results ${ }^{[18,20]}$.

For measuring the association of individual radiological parameter with functional results, we have taken criteria established by Stewart et al. ${ }^{[6]}$ into account; where they got excellent to good functional results with dorsal angulation kept $<10^{\circ}$, loss of radial inclination $<9^{\circ}$ and loss of radial height $<6 \mathrm{~mm}$.; We got a significant association with dorsal angulation $<10^{\circ}$ and loss of radial inclination $<9^{\circ}$ with functional result in a study included 50 patients. But we did not get significant association between loss of radial height $<6$ $\mathrm{mm}$ with functional result. But when loss of radial height was kept $<4 \mathrm{~mm}$, we got statistically significant association with functional result. When we compare our results with result by Bilic et al. [14], they found significant association with functional result with dorsal angulation $<10^{\circ}$, loss of radial inclination $<9^{0}$ and loss of radial length $<2 \mathrm{~mm}$. Altimissi et al. ${ }^{[8]}$ found radiological parameter of dorsal angulations $<15^{\circ}$, loss of radial inclination $<10^{\circ}$ and loss of radial height $<4 \mathrm{~mm}$ having significant association with functional result.

\section{Conclusion}

When we compare the functional result with that of anatomical result, we got a significant correlation between them that implies with better anatomical reduction of the fracture we have good to excellent functional outcome. When we compared the individual parameter with functional outcome at 6 month we got significant correlation between dorsal angulation $<10^{\circ}$ and loss of radial inclination $<9^{0}$ with functional result But there is no significant correlation of radial height $<6 \mathrm{~mm}$ with functional result. But we got a statistically significant association with loss of radial height $<4 \mathrm{~mm}$. Therefore this study recommends to keep dorsal angulation $<10^{\circ}$, loss of radial inclination $<9^{0}$ and loss of radial height to $<4 \mathrm{~mm}$; while reducing extra articular Colles' fracture for obtaining excellent to good results.

The limitation of our study were a small number of patients (50) and, the statistics analysis may likely to change with increasing sample size, hence defining the acceptable borderline parameters for radiological analysis might differ from studies to study which was reflected in discussion. Again obtaining a good anatomical reduction may not always be correct as described by Cooney, Dobyn and Lindscib, [21] who pointed out that soft tissue Injury was also equally responsible for the resulting stiffness which is not taken into account in this study may be the drawback.

\section{References}

1. Golden GN. Treatment and prognosis of Colles' fracture. Lancet. 1963; 1:511.

2. Court-Brown CM, caesar B. Epidemiology of adult fractures: A review. Injury. 2006; 37:691-697

3. Brogen E, Petranek M, Atroshi I. Incidence and charactarstic of distal radius fractures in southern swedish region. BMC musculo skeletal disord. 2007; 8:48

4. Cassebaum WH. Colles' fracture: A study of end results. JAMA. 1950; 143:963-5.

5. Golden GN. Treatment and prognosis of Colles' fracture. Lancet. 1963; 1:511-5.

6. Stewart HD, Innes AR, Burke FD. Functional castbracing for Colles' fractures: A comparison between castbracing and conventional plaster casts. J Bone Joint Surg. (Br]. 1984; 66-B:749-53.

7. Cooney WP. Management of Colles' fractures. J Hand Surg Br. 1989; 14:137-9.

8. Altissimi M, Antenucci R, Fiacca C, Mancini GB. Long term results of conservative treatment of fractures of the distal radius. Clin Orthop. 1986; (206):202-10.

9. Metz VM, Gilula LA. Imaging techniques for distal radius fractures and related injuries. Orthop Clin North Am. 1993; 24:217-28.

10. Mann FA, Wilson AJ, Gilula LA. Radiographic evaluation of the wrist: what does the hand surgeon want to know ? Radiology. 1992; 184:15-24.

11. Taleisnik J, Watson HK. Mid carpal instability caused by malunited fractures of the distal radius. J Hand Surg [Am]. 1984; 9:350-7.

12. Scheck M. Long-term follow-up of treatment of comminuted fractures of the distal end of the radius by transfixation with Kirschner wires and cast. Am J Orthop. 1962; 44-A:337-51.

13. Friberg S, Lundström B. Radiographic measurements on the radio-carpal joint in distal radial fractures. Acta Radiol Diagn (Stockh). 1976; 17:869-76.

14. Bilic R, Ruzic L, Zdravkovic V, Boljevic Z, Kovjanic J. Reliability of different methods of determination of radial shortening. Influence of ulnar and palmar tilt. J Hand Surg Br. 1995; 20:97-101.

15. Gartland JJ Jr, Werley CW. Evaluation of healed Colles' fractures. I Bone Joint Surg [Am]. 1951; 33-A:895-907.

16. Pool C. Colles' fracture: a prospective study of treatment. I Bone Joint Surg [Br]. 1973; 55-B:540-4.

17. Young BT, Rayan GM. Outcome following nonoperative treatment of displaced distal radius fractures in lowdemand patients older than 60 years. J Hand Surg Am. 2000; 25:19-28.

18. Solgaard S. Function after distal radius fracture. Acta Orthop Scand. 1988; 59:39-42.

19. Boyd LG, Horne JG. The outcome of fractures of the distal radius in young adults. Injury. 1988; 19:97-100

20. Jenkins NH, Mintowt-Czyz WJ. Mal-union and disfunction-in Colles' fracture. J Hand Surg Br. 1988; 13:291-3.

21. Coosiey WP Ill, Dobyns JH, LInscbeld RL. Complications of Colles' fractures. I Bone Joint Surg (Am]. 1980; 62-A:613-9. 